\title{
Seasonal Variations of Gonadotropins and Prolactin in the Laboratory Rat. Role of Maternal Pineal Gland
}

\author{
N. VÁZQUEZ, E. DÍAZ, C. FERNÁNDEZ, V. JIMÉNEZ ${ }^{1}$, A. ESQUIFINO", \\ B. DÍAZ
}

Department of Biology, Section of Physiology, Faculty of Medicine, University Oviedo, Oviedo, ${ }^{1}$ Department of Biochemistry and Molecular Biology III, Faculty of Medicine, Complutense

University, Madrid, Spain

Received October 11, 2005

Accepted February 1, 2006

On-line available February 23, 2006

\begin{abstract}
Summary
The laboratory rat, a non-photoperiodic rodent, exhibits seasonal fluctuations of melatonin. Melatonin has been found to be readily transferred from the maternal to the fetal circulation. No data exist on the possible influence of maternal pineal gland upon seasonal variations of the offspring. The aim of the present study was to asses the influence of the maternal melatonin rhythm on the offspring postnatal development of the reproductive hormones LH, FSH and prolactin. Male offspring from control, pinealectomized (PIN-X) and PIN-X + melatonin (PIN-X+MEL) mother Wistar rats were studied at 21,31, and 60 days of age. Seasonal age-dependent variations were found for all hormones studied in control offspring but PIN-X offspring showed a tendency to have reduced duration or altered seasonal variations. Maternal melatonin treatment to PIN-X mothers partially restored the effect of pinealectomy. The chronological study of LH, FSH, and prolactin in PIN-X offspring also showed an altered pattern as compared to control-offspring. Melatonin treatment to the mothers partially restored the developmental pattern of reproductive hormones. Results of this study indicate that maternal pineal gland of the laboratory rat is involved in the seasonal postnatal development variations of reproductive hormones of the offspring.
\end{abstract}

Key words

Maternal pineal gland $\bullet$ Seasonal variations $\bullet$ Gonadotropins $\bullet$ Prolactin $\bullet$ Developmental pattern $\bullet$ Laboratory rat

\section{Introduction}

The synthesis of melatonin in the pineal gland exhibits a circadian rhythm with the highest concentration of this indolamine occurring during the night (Reiter 1980). Also, melatonin shows fluctuations throughout the year, with higher plasma and pineal levels during the winter months as compared to the summer months (Martínez-Soriano et al. 2002). A correlation between melatonin and reproductive functions has been described in mammals (Lang 1986). The regulation of melatonin reproductive actions was proven to be mediated by a membrane receptor in the respective target cells (Vaněček et al. 1987). However, the high lipid solubility of this indolamine allows its easy access to the interior of cells and body fluids. Higher amounts of melatonin in preovulatory follicles than in serum were found in women (Brzezinski et al. 1987). Melatonin can cross all 
body barriers including the placenta. Developmental studies on the enzymes that synthesize melatonin indicate that it is probably not synthesized in rats before day 10 of life. Nevertheless, melatonin could be present in animals younger than 10 days of age by transfer from the mother since ${ }^{3} \mathrm{H}$-acetyl-melatonin injected into a pregnant rat could be detected in the fetuses (Klein 1972). Melatonin has been found to be readily transferred at a rapid rate from the maternal to the fetal circulation also in near-term women (Okatani et al. 1998).

The participation of maternal pineal gland in the regulation of rat reproductive functions of male offspring has been suggested. Testicular function of the rat after exposure of the mother to a short photoperiod beginning before conception is decreased by maternal pinealectomy (Jarrige et al. 1992). The pinealectomy in mother rats and melatonin treatment during pregnancy can act on fetal development and influence the postnatal ontogeny of the hormones involved in the neuroendocrine-reproductive axis in developing rats (Fernández et al. 1995, Díaz et al. 1995, 1999, Okatani et al. 2001). The suprachiasmatic nucleus of the hypothalamus (SCN) is a likely candidate to mediate the influence of melatonin from pineal gland on the secretion of hormones by the hypothalamopituitary axis. The laboratory rat, a non-photoperiodic rodent, raised under rigorously controlled laboratory conditions through generations also exhibits seasonal fluctuations of melatonin or pineal gland synaptic body number (Bartsch et al. 1994, 2001, Martínez-Soriano et al. 2002). Pituitary, gonadal hormones (Kinson and Liu 1973, Mock et al. 1975, 1978, Wong et al. 1983) or brain neuropeptides (Bissette et al. 1995, Vázquez et al. 2004a,b) all exhibit rhythms. The annual rhythm of the nuclear activity of the ventromedial hypothalamic nucleus was modified by pinealectomy and superior cervical ganglionectomy (Peschke et al. 2000). All procedures that inactivated the pineal gland or reduced the content of melatonin were followed by an increase of the cell nuclei of the suprachiasmatic nucleus (SCN) of the hypothalamus. The degree of this negative correlation between the pineal gland and the central nervous system was seasonally dependent, the lowest effect was observed in short-day conditions (Peschke et al. 1996). These results suggest a role of the pineal gland on seasonal variations in the laboratory rat as well as in seasonal breeders. No data exist on the possible influence of maternal pineal gland upon seasonal variations of the offspring.

Melatonin binding sites have been found in the
SCN of the rat (Weaver et al. 1989); they may be involved in the regulation of seasonal rhythms regulated by melatonin (Zucker et al. 1991). The maternal melatonin signal to the fetus and to the developing neonate may be an essential factor for the emerging circadian or seasonal systems of both the infant and the adult rat. This hypothesis is supported by the widespread presence of melatonin in rat fetal tissues (Klein 1972) or melatonin receptors in the human fetus, particularly in the SCN (Yuan et al. 1991).

The aim of the current study was to asses the disturbances of the rat maternal melatonin rhythm in the offspring postnatal development of the reproductive hormones LH, FSH and prolactin. Elucidation of these prenatal messages in relationship to the season of the year should provide an interesting perspective on the neuroendocrinology of the mammalian reproduction and seasonality.

\section{Methods}

\section{Laboratory animals}

Female Wistar rats from our colony of the Faculty of Medicine, University of Oviedo, Spain, were housed under controlled environmental conditions 12:12 photoperiod (lights on at $08.00 \mathrm{~h}$ ), with a room temperature of approximately $23{ }^{\circ} \mathrm{C}$ in a humiditycontrolled environment, and fed standard rat chow and water ad libitum. Mother rats were divided into the following groups: control $(\mathrm{n}=46)$, pinealectomized (PIN$X)(n=35)$ and pinealectomized + melatonin treatment (PIN-X+MEL) $(n=43)$. The study was performed during the four seasons of the year. For this purpose, the experiment was carried out from fall 2000 until winter 2002. Mother rats were mating pairs of one male with two females; possible pregnancy was monitored by the presence of vaginal spermatozoa. During the pregnancy, mother rats were kept individually in polypropylene cages, at the beginning of each season, on day 20 of December, March and June and 22 of September. Keeping in mind that pregnancy in the rat lasts 21 days, an offspring up to 60 days of age could be studied in the corresponding three months for each season and studied in the last two months of each season. At delivery, litter sex and number of pups were recorded, and in order to obtain uniformity in the development of the pups, on the day of birth each litter was adjusted to 12 pups per dam by cross-fostering some pups from larger litters within treatment groups. Pups remained with the mother until 
weaning on day 21 (birth = day 0). To study male offspring we followed the classification (Ojeda et al. 1980) used for postnatal maturation: a) juvenile or prepubertal period, from 21 to 35 days of age; animals were studied on days 21 and 31 ; b) pubertal period, from day 35 to 55-60 days of age, animals being examined on day 60. At the mentioned ages, between 9:30 and 10:30 h, the animals were brought from the adjacent animal room in the polypropylene cage to a laboratory and were decapitated with a guillotine. After head removal, the sink, guillotine, and counter top were rinsed with copious amounts of water to remove the odor of blood before the next animal was brought in.

\section{Melatonin treatment and pinealectomy}

Considering previous findings (Klein 1972) in which $20 \mathrm{nCi}$ of ${ }^{3} \mathrm{H}$-acetyl-melatonin was administered to pregnant rats, and that each fetus contained slightly more than $0.1 \%$ (20 nCi), of the injection dose, $100 \mu \mathrm{g} / 100 \mathrm{~g}$ body weight were used as a standard dose in the present study. Melatonin (M-5250, Sigma Chemical Co, St Louis, MO) was dissolved in a small volume of absolute ethanol $(0.04 \mathrm{ml})$ and diluted in $0.9 \% \mathrm{NaCl}$ to a dose of $100 \mu \mathrm{g} / 100 \mathrm{~g}$ body weight. Melatonin treatment was given by sc injection at the end of the light phase to mother rats, and daily throughout pregnancy. Control and PIN-X mother rats received ethanol/saline alone.

Pinealectomy was carried out according to the procedure previously described (Pérez-Casas et al. 1997). After surgery, the animals were allowed to recover for 15 days. All mothers used in the study were examined after weaning to verify the completeness of the pinealectomy. Offspring of these mothers with failed pinealectomy were discarded, and new mothers were prepared for the next year at the same season.

\section{Radioimmunoassay of gonadotropins and prolactin}

Plasma LH, FSH and prolactin levels were measured by specific RIAs using second antibodyfacilitated separation and reagents kindly provided by the National Hormone and Pituitary Program (NIADDK, Bethesda, MD). The assays were validated in our laboratory as previously described (Tresguerres and Esquifino 1981). All samples were run in the same assay for each hormone to avoid interassay variations.

\section{Statistical analysis}

Data of each age group were adjusted to a normal distribution test before being used in the statistical analysis. A 99 percentage of accuracy to normal distribution was required. Statistical analysis was performed using the SPSS version 10.0 (SPSS Inc., Chicago, IL). Results were expressed as mean \pm SEM. Comparisons among data of hormone concentrations at each age (21-, 31- and 60-day-old) and groups (control-, PIN-X- and PIN-X+MEL-offspring) studied were determined by 3-way ANOVA. There was a significant interaction effect among season, group of treatment and age. For LH (F: 4.636; p: 0.0000003), FSH (F: 2.905; p: 0.001), prolactin (F:2.347; p: 0.006). Then, individual comparisons among seasons, groups of treatment or age were made by Student's t-test. Significant differences were noted by the following symbols: ${ }^{\#} \mathrm{p}<0.01,{ }^{\# \#} \mathrm{p}<0.05$ for seasonal differences; * $\mathrm{p}<0.01$, ** $\mathrm{p}<0.05$ for differences among groups of treatment; ${ }^{\mathrm{a}} \mathrm{p}<0.01$, ${ }^{\mathrm{b}} \mathrm{p}<0.05$ for the chronological study, i.e. the differences among ages.

\section{Results}

\section{LH concentrations}

Seasonal variations (Fig. 1): At 21 days of age LH showed significantly higher values $(p<0.01)$ in control-offspring during fall and winter as compared to spring and summer, and in PIN-X-offspring during winter as compared to the other three seasons. PIN-X+MELoffspring showed significantly higher LH $(p<0.01)$ concentrations during summer as compared to the other three seasons studied and during fall and winter $(\mathrm{p}<0.05)$ as compared to spring. At 31 days of age, LH showed significantly higher values $(\mathrm{p}<0.01, \mathrm{p}<0.05)$ in controloffspring during summer, fall and winter than during spring and in PIN-X-offspring during fall and winter than in spring and summer. At 60 days of age $\mathrm{LH}$ concentrations in PIN-X-offspring during summer showed significantly higher values $(\mathrm{p}<0.05)$ as compared to spring.

At 21 days of age during summer PIN-X+MELoffspring showed significantly higher $L H$ values $(p<0.01)$ than control- and PIN-X-offspring. PIN-X-offspring during fall showed significantly lower $(p<0.01, p<0.05)$ $\mathrm{LH}$ values, and during winter significantly higher $\mathrm{LH}$ values $(p<0.01)$ as compared to control- and PIN-XMEL-offspring. At 31 days of age, during spring PIN$\mathrm{X}+\mathrm{MEL}$-offspring showed significantly higher $(\mathrm{p}<0.05)$ LH values as compared to control group. During summer, PIN-X-offspring, showed significantly lower $(\mathrm{p}<0.01$, $\mathrm{p}<0.05$ ) values as compared to control- and PIN-X+ 


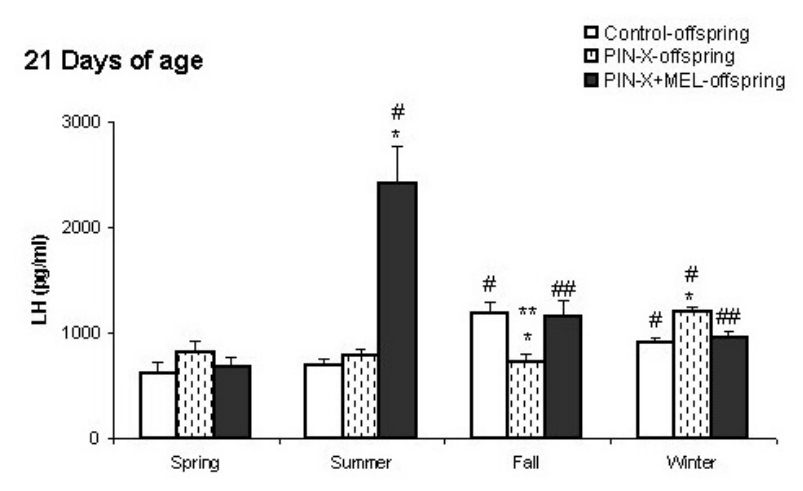

31 days of age

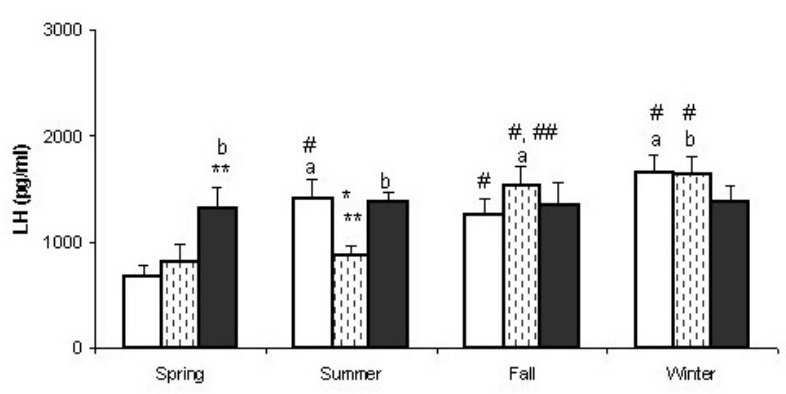

60 days of age

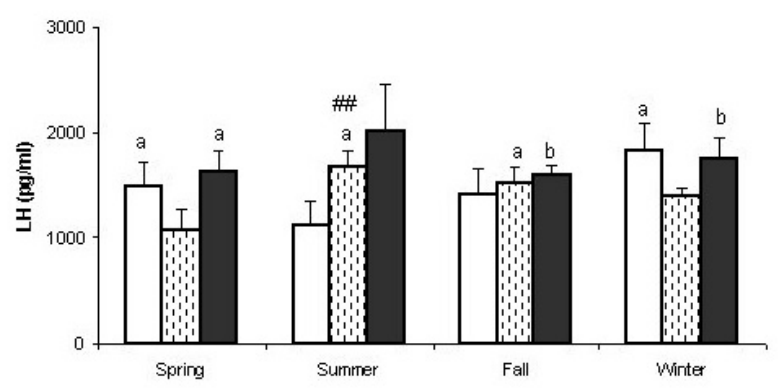

Fig. 1. Serum LH concentrations throughout the four seasons of the year of male offspring of mother rats: control, PIN-X or PIN$X+M E L$ during pregnancy ( $100 \mu \mathrm{g} / 100 \mathrm{~g}$ body weight). Values are presented as mean + SEM. Sample sizes are: spring: 21 days $(n=18-24), 31$ days $(n=14-26), 60$ days $(n=9-14)$, summer: 21 days $(n=11-19), 31$ days $(n=16-17), 60$ days $(n=7-12)$, fall: 21 days $(n=13-31), 31$ days $(n=14-23), 60$ days $(n=9-23)$, winter: 21 days $(n=18-30), 31$ days $(n=14-16), 60$ days $(n=8-13)$.

Seasonal study. 21 Days) control: \#: $p<0.01$ vs. spring and summer; PIN-X: \#: $p<0.01$ vs. spring, summer and fall; PIN$X+M E L: ~ \#: p<0.01$ vs. spring, fall and winter, \#\#: $p<0.05$ vs. spring. 31 Days) control: \#: $p<0.01$ vs. spring; PIN-X: \#: $p<0.01$ vs. spring and summer, \#\#: $p<0.05$ vs. spring. 60 Days) PIN-X: \#\#: $p<0.05$ vs. spring.

Differences among groups of treatment. 21 Days) summer: *: $\mathrm{p}<0.01$ vs. PIN-X and control. Fall $*: \mathrm{p}<0.01$ vs. control, $* *$ : $\mathrm{p}<0.05$ vs. PIN-X+MEL. Winter: $*: p<0.01$ vs. PIN-X+MEL and control. 31 Days) spring: $* *$ : $p<0.05$ vs. control. Summer: $*$ : $\mathrm{p}<0.05$ vs. control, $* *$ : $\mathrm{p}<0.01$ vs. PIN-X+MEL.

Chronological study. Control: spring: $a: p<0.01$ vs. 21 and 31 . Summer and winter: a: $p<0.01$ vs. 21. PIN-X: Summer: a: $p<0.01$ vs. 21 and 31 . Fall and winter: $a: p<0.01, b: p<0.05$ vs. 21. PIN-X+MEL: $a$ : in the four seasons: $p<0.01, b: p<0.05$ vs. 21.
MEL-offspring.

Chronological study: LH values significantly increased $(\mathrm{p}<0.01, \mathrm{p}<0.05)$ from 21 to 31 days in controloffspring during summer and winter; in PIN-X-offspring during fall and winter and in PIN-X+MEL-offspring during spring. Only during summer, in PIN-X+MELoffspring $\mathrm{LH}$ values at 31 days of age were significantly lower than at 21 days. LH values at 31 days of age were similar to those at 60 days of age in the three groups in the four seasons, LH values increased only from 31 to 60 days in control-offspring during spring and in PIN-Xoffspring during summer. Significantly higher LH values $(\mathrm{p}<0.01, \mathrm{p}<0.05)$ at 60 days compared to 21 days were present in the four seasons except for control-offspring during summer and fall, for PIN-X-offspring during spring and winter, and for PIN-X+MEL-offspring during summer.

\section{FSH concentrations}

Seasonal variations (Fig. 2): FSH at 21 days of age showed significantly higher concentrations $(\mathrm{p}<0.01$, $\mathrm{p}<0.05$ ) in PIN-X-offspring during spring as compared to fall and winter, and in PIN-X+MEL-offspring, during fall, as compared to the other three seasons. At 31 days of age, FSH showed significantly higher values $(\mathrm{p}<0.01$; $\mathrm{p}<0.05$ ) in PIN-X-offspring during winter as compared to spring and summer and in PIN-X+MEL-offspring during spring, summer and fall as compared to winter. At 60 days of age, FSH showed significantly higher values $(p<0.05)$ in control-offspring during summer and fall as compared to winter, and in PIN-X-offspring, during spring and winter as compared to fall.

At 21 days of age during spring and summer, PIN-X-offspring showed significantly higher $(\mathrm{p}<0.01$, $\mathrm{p}<0.05$ ) values as compared to PIN-X+MEL-offspring. During fall, PIN-X+MEL-offspring showed significantly higher $(\mathrm{p}<0.01)$ values as compared to control and PIN$\mathrm{X}$-offspring. At 31 days of age, PIN-X offspring showed during summer significantly lower $(\mathrm{p}<0.05, \mathrm{p}<0.01)$ values as compared to control- and PIN-X+MELoffspring and during winter, significantly higher $(\mathrm{p}<0.01)$ values as compared to PIN-X+MEL-offspring. At 60 days of age during spring PIN-X+MEL-offspring showed significantly lower $(p<0.05)$ values as compared to control-offspring. During summer, PIN-X-offspring had significantly lower $(\mathrm{p}<0.01)$ values as compared to control-offspring. During fall, PIN-X- and PIN-X+MELoffspring showed significantly lower concentrations $(p<0.01)$ as compared to control-offspring. 


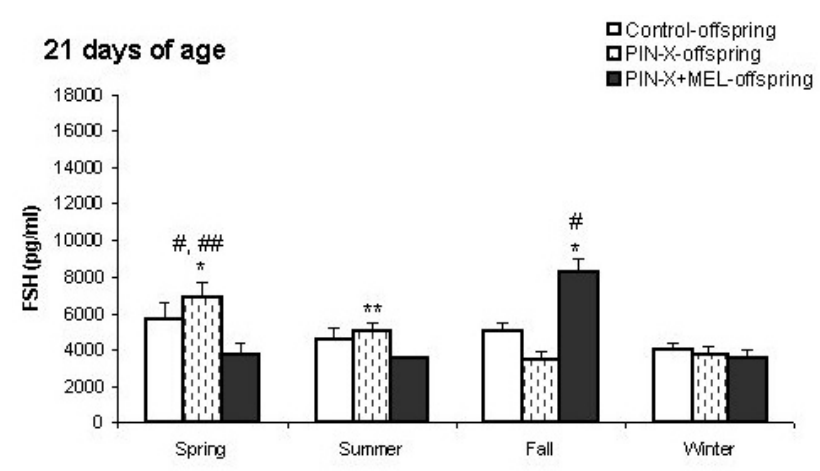

31 days of age

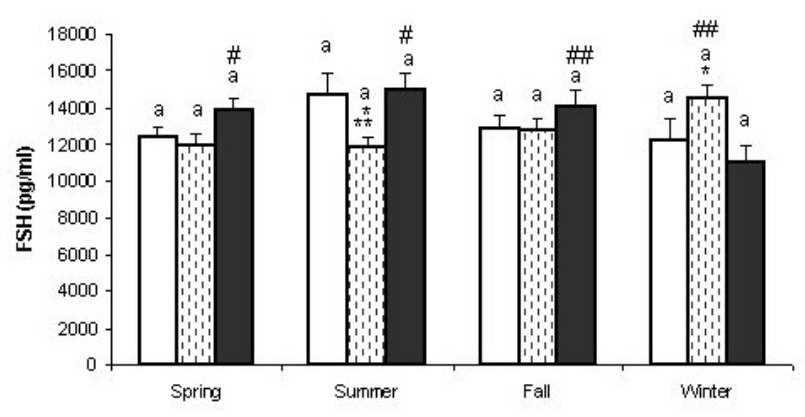

60 days of age

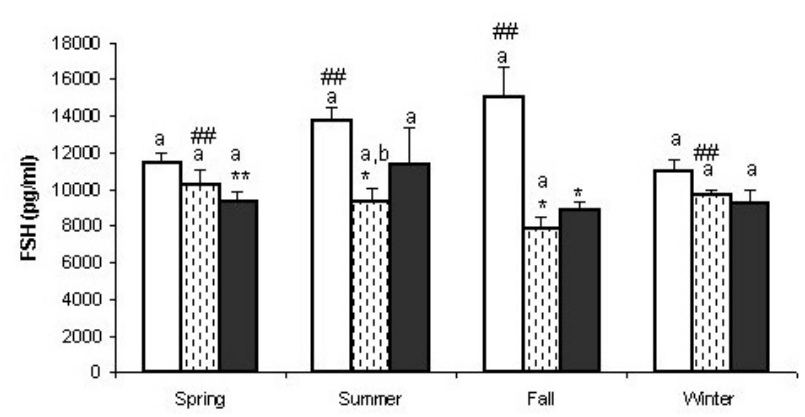

Fig. 2. Serum FSH concentrations in the same groups than in Figure 1. Values are presented as mean + SEM. Sample sizes are: spring: 21 days $(n=6-8), 31$ days $(n=14-25), 60$ days $(n=9$ 14), summer: 21 days $(n=5-6), 31$ days $(n=16-17), 60$ days $(n=7-12)$, fall: 21 days $(n=7-11), 31$ days $(n=15-24), 60$ days $(n=11-23)$, winter: 21 days $(n=4-7), 31$ days $(n=16-17), 60$ days $(n=8-12)$.

Seasonal study. 21 Days) PIN-X: \#: $p<0.01$ vs. fall, \#\#: $p<0.05$ vs. winter; PINX+ MEL: \#: $\mathrm{p}<0.01$ vs. spring, summer and winter. 31 Days) PIN-X: \#\#: $p<0.05$ vs. spring and summer; PIN-X+MEL: \#: $p<0.01$, \#\#: $p<0.05$ vs. winter. 60 Days) control: \#\#: $p<0.05$ vs. winter; PIN-X: \#\#: $p<0.05$ vs. fall. Differences among groups of treatment. 21 Days) Spring and summer: *: $\mathrm{p}<0.01, * *: \mathrm{p}<0.05$ vs. PIN-X+MEL. Fall: $*: \mathrm{p}<0.01$ vs. PIN-X and control. 31 Days) Summer and winter: $*$ : $p<0.01$ vs. PIN-X+MEL. Summer: $* *$ : $\mathrm{p}<0.05$ vs. control. 60 Days) Spring: $* *: p<0.05$ vs. control. Summer and fall: $*: p<0.01$ vs. control.

Chronological study. Control: in the four seasons: $a: p<0.01$ vs. 21. PIN-X: spring: $a: p<0.01$ vs. 21 . Fall and winter: $a: p<0.01$ vs. 21 and 31 . Summer: a: $p<0.01$ vs. $21, b: p<0.05$ vs 31 . PIN$X+M E L$ : spring: $a: p<0.01$ vs. 21 and 31 . Summer and winter: $p<0.01$ vs. 21 . Fall: $a: p<0.01$ vs. 21 and 60 .
Chronological study: FSH values significantly increased at 31 and 60 days of age in control-offspring as compared to 21 days in four studied seasons. In PIN-Xoffspring FSH values also significantly increased $(p<0.01)$ at 31 and 60 days as compared to 21 days of age, but during summer, fall and winter, FSH values at 60 days were significantly lower $(\mathrm{p}<0.01, \mathrm{p}<0.05)$ than at 31 days. In PIN-X+MEL-offspring values at 31 and 60 days of age were significantly higher $(\mathrm{p}<0.01)$ than at 21 days, only during fall values at 60 days of age were not significantly higher than at 21 days. And during spring and fall FSH values at 60 days of age were significantly lower $(\mathrm{p}<0.01)$ than at 31 days.

\section{Prolactin concentrations}

Seasonal variations (Fig. 3): At 21 days of age prolactin concentrations in PIN-X+MEL-offspring showed significantly higher $(\mathrm{p}<0.01)$ values during summer as compared to spring, fall and winter, and during winter and fall as compared to spring. At 31 days of age, prolactin showed significantly higher values $(\mathrm{p}<0.05, \mathrm{p}<0.01)$ in control-offspring during spring and fall as compared to summer and winter, in PIN-Xoffspring, during fall as compared to spring and in PIN$\mathrm{X}+\mathrm{MEL}-$ offspring during summer and fall as compared to spring and winter. At 60 days of age during summer, prolactin showed significantly higher values $(p<0.05)$ in control-offspring as compared to spring and winter, and in PIN-X-offspring during fall as compared to spring.

At 21 days of age, during spring, PIN-X+MELoffspring showed significantly lower $(\mathrm{p}<0.05)$ values as compared to control-offspring and during summer PIN$\mathrm{X}$-offspring had significantly lower $(\mathrm{p}<0.01)$ values as compared to PIN-X+MEL-offspring. During fall PIN-XMEL-offspring showed significantly lower $(\mathrm{p}<0.01$, $\mathrm{p}<0.05$ ) values as compared to control- and PIN-Xoffspring. At 31 days of age, during spring PIN-X- and PIN-X+MEL-offspring showed significantly lower $(\mathrm{p}<0.01)$ values as compared to control-offspring. During summer, PIN-X+MEL-offspring showed significantly higher $(\mathrm{p}<0.01)$ values compared to control- and PIN-Xoffspring.

Chronological study: Prolactin values in controloffspring significantly increased $(p<0.01, p<0.05)$ from 21 to 31 days in spring, fall and winter, and from 31 to 60 days in summer, fall and winter. In PIN-X+MELoffspring prolactin values significantly increased ( $<<0.01$, $\mathrm{p}<0.05)$ from 21 to 31 up to 60 days in the four seasons. In PIN-X-offspring a delay in the increase of prolactin 

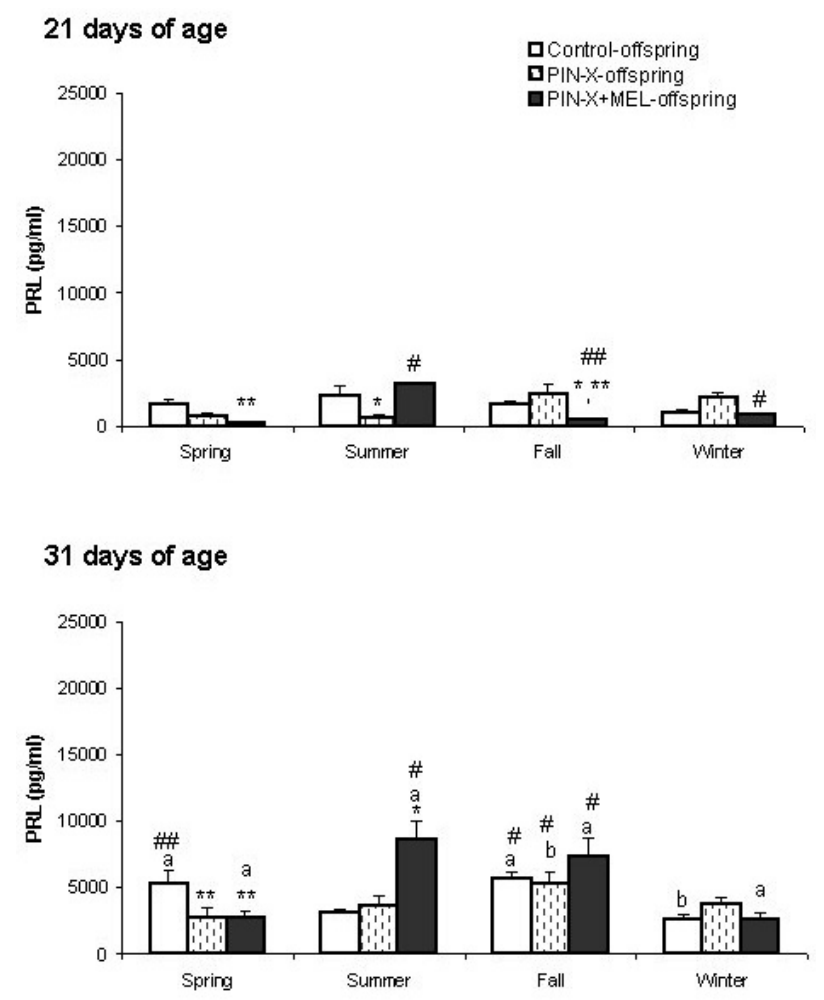

60 days of age

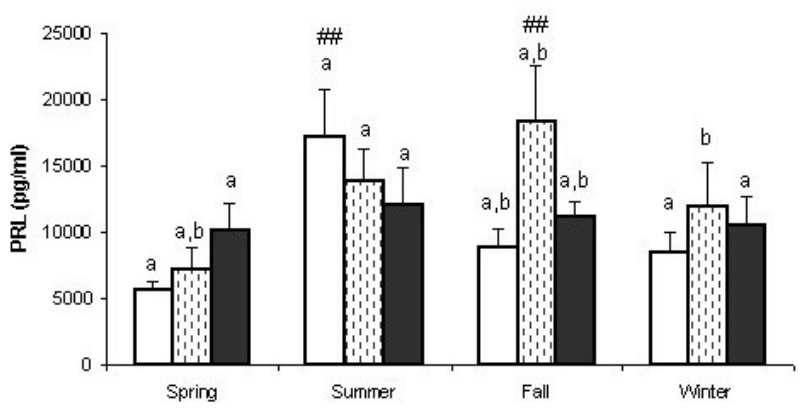

Fig. 3. Serum PRL concentrations in the same groups than in Figure 1 . Values are presented as mean + SEM. Sample sizes are: spring: 21 days $(n=4-6), 31$ days $(n=14-26), 60$ days $(n=9$ 14), summer: 21 days $(n=4-7), 31$ days $(n=16-17), 60$ days $(n=5-12)$, fall: 21 days $(n=8-12), 31$ days $(n=14-24), 60$ days $(n=11-12)$, winter: 21 days $(n=6-12), 31$ days $(n=15-17), 60$ days $(n=8-13)$.

Seasonal study. 21 Days) PIN-X+MEL: \#: $p<0.01$ summer vs. spring, fall and winter, winter vs. spring, \#\#: $p<0.05$ vs. spring. 31 Days) control: \#: $\mathrm{p}<0.01, \# \#: \mathrm{p}<0.05$ vs. summer and winter; PIN-X: \#: $p<0.01$ vs. spring; PIN-X+MEL: $\#: p<0.01$ vs. spring and winter. 60 Days) control: \#\#: $p<0.05$ vs. spring and winter; PIN-X: \#\#: $p<0.05$ vs. spring.

Differences among groups of treatment. 21 Days) spring: **: $\mathrm{p}<0.05$ vs. control. Summer: $*: \mathrm{p}<0.01$ vs. PIN-X+MEL. Fall: *: $\mathrm{p}<0.01$ vs. control, $* *$ : $\mathrm{p}<0.05$ vs. PIN-X. 31 Days) spring: $* *$ : $\mathrm{p}<0.05$ vs. control. Summer: *: $p<0.01$ control- and PIN-X.

Chronological study: control: Spring: $a: p<0.01$ vs. 21 . Summer: a: $p<0.01$ vs. 21 and 31 . Fall: a: $p<0.01$ vs. $21, b: p<0.05$ vs. 31. Winter: $a: p<0.01$ vs. 21 and $31, b: p<0.05$ vs. 21 . PIN-X: Spring: $a: p<0.01$ vs. $21, b: p<0.05$ vs. 31 . Summer: $a: p<0.01$ vs. 21 and 31 . Fall: $a: p<0.01$ vs. $21, b: p<0.05$ vs. 21 and 31 . Winter: $b: p<0.05$ vs. 21 . PIN-X+MEL: spring and winter: $a$ : $p<0.01$ vs. 21 and 31 . Summer: a: $p<0.01$, vs. 21 . Fall: a: $p<0.01$ vs. $21, b: p<0.05$ vs. 31 . values from 21 to 31 days was observed in spring, summer and winter. Prolactin values significantly increased $(\mathrm{p}<0.05)$ from 21 to 31 days only during fall. A significant increase $(p<0.01, p<0.05)$ was observed from 31 to 60 days of age in the four seasons.

\section{Discussion}

The possible involvement of the maternal pineal gland on the seasonal variations of reproductive hormones has not been studied before. Our results of LH in control-offspring show that seasonal variations were observed at prepubertal ages showing the higher values during fall and winter at 21 days of age and during summer, fall and winter at 31 days of age. However, no seasonal variations were observed in the adult age, at 60 days. Although seasonal variations were still observed, LH values were reduced at both prepubertal studied ages in PIN-X-offspring. A delay in the switch on but not in the switch off was suggested by the results on the mechanisms involved in the normal postnatal seasonal hormones secretion. This was due to the fact that when in control-offspring LH showed increased values, in PIN-Xoffspring the increase was observed a season later. In fact, at 21 days of age during fall and 31 days during summer, PIN-X-offspring exhibited significantly lower values than control offspring, and melatonin treatment to PIN-X mothers restored this LH developmental pattern. The delay in the LH developmental pattern observed in PIN-X-offspring indicates that maternal melatonin signal to pups influences the reproductive axis and that it may be necessary for a normal postnatal development. The importance of maternal melatonin signal to the pups has also been described in both female and male rat offspring of PIN-X mothers, in which delayed sexual maturation was observed (Jarrige et al. 1992, Díaz et al. 1995, Fernández et al. 1995, Okatani et al. 2001). On the other hand, although melatonin treatment in PIN-X mothers increased the LH levels compared with those in PIN-Xoffspring, it also resulted in disturbances of the $\mathrm{LH}$ developmental pattern. These were observed just before the normal increase of the hormone occurred, in summer at 21 days, and in spring at 31 days of age. No seasonal differences in PIN-X+MEL-offspring were observed at 31 days of age, due to the increase of LH values during spring.

Our results also indicate that the $\mathrm{LH}$ developmental pattern was season-dependent in controloffspring, since only during winter and spring 
significantly increased values were observed at 60 days of age as compared with those at 21 days. During summer and fall at 60 days of age, LH values were at the same level as 21 days of age. Maternal PIN-X completely altered this developmental pattern as no significantly increased LH values during winter and spring at 60 days of age were observed. Instead, they were observed during summer and fall. The combination of maternal PIN$\mathrm{X}+\mathrm{MEL}$ treatment partially restored this $\mathrm{LH}$ developmental pattern showing again during winter, spring and fall at 60 days of age significantly higher values than at 21 days of age. Previous findings point out that the pineal melatonin rhythm appears to serve as a internal signal that is capable of regulating a variety of seasonal variations in physiology and behavior (Goldman 1999) or also as a seasonal transducer (Brainard et al. 1982). The importance of the mother in setting the biological clock for melatonin synthesis in the newborn rat in a way independent of the environmental lighting schedule has also been suggested (Deguchi 1978).

No seasonal differences for FSH concentrations in control-offspring at the pubertal ages studied were found, except at 60 days of age. However, maternal PIN-X produced alterations in the offspring during the prepubertal ages. Significantly increased values observed at 21 days during spring or at 31 days during winter or significantly reduced values during fall at 60 days, resulted in seasonal variations. The influence of maternal PIN-X was observed during summer at the three ages studied, showing at 31 and 60 days significantly lower values than in control-offspring, indicating delayed sexual maturation. Maternal melatonin to PIN-X mothers partially restored the effect of PIN-X, since no significant differences were found during summer in comparison to control-offspring. Differences were observed mainly during fall or spring, or at 31 days of age, when values during winter were significantly lower than during spring, summer and fall.

The onset of pubertal development of male rats starts with the "juvenile period", which could be called the FSH period, with peak plasma values between 30 and 35 days of age (Payne et al. 1977). Similarly, in our study, FSH concentrations of control-offspring significantly increased from 21 to 31 days of age showing the same level as at 60 days of age, adult age, in the four seasons studied. PIN-X-offspring altered this developmental pattern showing during summer, fall and winter, decreased FSH levels at 60 days of age as compared with those at 31 days. PIN-X+MEL offspring resulted in a partially restored developmental pattern, since only during fall and winter, FSH values at 60 days of age were lower than at 31 days. These results again suggest that a season-dependent melatonin influence on FSH is operative already during fetal life.

Prolactin levels start to increase at 31 days of age. At this age, seasonal differences were observed in control-offspring, with higher values during spring and fall. Our data indicate that the profile of serum prolactin secretion exhibits seasonal variations in the laboratory rat as in the ewe or mare, which are seasonal breeders (Fitzgerald et al. 2000, Santiago-Moreno et al. 2000). Seasonal differences in PIN-X-offspring were also observed at 31 days of age, but values increased only during fall. As for LH they were reduced in a season length. At 60 days of age, seasonal differences were observed in control-offspring, with higher values during summer, while in PIN-X-offspring higher values were present during fall. The influence of melatonin treatment to PIN-X mothers was observed mainly at the prepubertal ages. At 21 days of age, the rats showed seasonal differences, with significantly lower values during spring and fall. At 31 days of age, the highest values were observed during summer. Prolactin levels in controloffspring showed a tendency toward increased values at 21 to 31 days up to 60 days of age. Only during summer values at 21 to 31 days of age did not increase. However, in PIN-X-offspring a delay in the increase of prolactin levels was observed during spring, summer and winter. Maternal PIN-X+MEL treatment resulted in a chronological developmental pattern similar to controloffspring, except during summer when values from 21 to 31 days of age also increased. The influence of the maternal pineal gland during pregnancy of the rat on the ontogeny of reproductive hormones, again became evident from the altered postnatal development of prolactin levels. Previous studies showed that in the seasonal breeder white-tailed deer PIN-X altered the seasonal profile of serum prolactin and the pituitary responssiveness to thyrotropin releasing hormone (Schulte et al. 1981).

The intrinsic cause for the seasonal variations in the reproductive hormones in the laboratory rat could be due to endogenous mechanisms. This is supported by the changes in melatonin secretion with peak values observed in August and May in rats (Bartsch et al. 2001). Similarly, in humans peak values of melatonin were observed during June and November, when a combination of high day length stability and low values 
of the vertical component of the geomagnetic field were recorded (Bergiannaki et al. 1996). The suprachiasmatic nucleus may be a likely candidate to mediate the influence of melatonin from the pineal gland on the secretion hormones in the hypothalamo-pituitary axis. In the suprachiasmatic nucleus of the rat, melatonin binding sites have been localized and are though to be responsible for a melatonin feedback mechanism between pineal gland and suprachiasmatic nucleus (Weaver et al. 1989, Reuss 1996). They may be involved in the regulation of seasonal rhythms induced by melatonin (Zucker et al. 1991). However, the mechanisms underlaying the effects of exogenous melatonin in the $\mathrm{SCN}$ endogenous rhythmicity are not clarified yet.

In conclusion, our results indicate for the first time that the maternal pineal gland of the laboratory rat is involved in the seasonal postnatal development profile of reproductive hormones of the offspring.

\section{Acknowledgements}

The authors wish to express their gratitude to the NIADDK, NHPP and the University of Maryland, School of Medicine for the provision of radioimmunoassay materials of LH, FSH and prolactin and to Dr. L. Debeljuk for his grammatical assistance.

\section{References}

BARTSCH H, BARTSCH C, MECKE D, LIPPERT TH: Seasonality of pineal melatonin production in the rat: possible synchronization by the geomagnetic field. Chronobiol Int 11: 21-26, 1994.

BARTSCH H, BARTSCH C, DEERBERG F, MECKE D: Seasonal rhythms of 6-sulphatoxymelatonin (aMT6s) excretion in female rats are abolished by growth of malignant tumors. J Pineal Res 1: 57-61, 2001.

BERGIANNAKI J, PAPARRIGOPOULES TJ, STEFANIS CN: Seasonal pattern of melatonin excretion in humans: relationship to daylength variation rate and geomagnetic field fluctuations. Experientia 52: 253-258, 1996.

BISSETTE G, GRIFF D, CARNES M, GOODMAN B, LAVINE M, LEVANT B: Apparent seasonal rhythms in hypothalamic neuropeptides in rats without photoperiod changes. Endocrinology 136: 622-628, 1995.

BRAINARD GC, PETTERBORG LJ, RICHARDSON BA, REITER RJ: Pineal melatonin in Syrian hamsters: circadian and seasonal rhythms in animals maintained under laboratory and natural conditions. Neuroendocrinology 35: 342-348, 1982.

BRZEZINSKI A, SEIBEL MM, LYNCH HJ, DENG M-H, WURTMAN RJ: Melatonin in human preovulatory follicular fluid. $J$ Endocrinol Metab 64: 865-867, 1987.

DEGUCHI T: Ontogenesis of circadian rhythm of melatonin synthesis in pineal gland of rat. $J$ Neural Transm 13 (Suppl): 115-128, 1978.

DÍAZ B, COLMENERO MD, DÍAZ E, ARCE A, ESQUIFINO A, MARÍN B: Effect of pinealectomy and melatonin treatment during pregnancy on the sexual development of the female and male rat offspring. Eur $J$ Endocrinol 132: 765-770, 1995.

DÍAZ B, DÍAZ E, COLMENERO MD, ARCE A, ESQUIFINO A, MARÍN B: Maternal melatonin influences rates of somatic and reproductive organs postnatal development of male rat offspring. Neuroendocrinol Lett 20: 69-76, 1999.

FERNÁNDEZ B, DÍAZ E, COLMENERO MD, DÍAZ B: Maternal pineal gland participates in prepubertal rat's ovarian oocyte development. Anat Rec 243: 461-465, 1995.

FITZGERALD BP, DAVISON LA, MCMANUS CJ: Evidence for a seasonal variation in the ability of exogenous melatonin to suppress prolactin secretion in the mare. Dom Animal Endocrinol 18: 395-408, 2000.

GOLDMAN BD: The circadian timing system and reproduction in mammals. Steroids 64: 679-685, 1999.

JARRIGE JF, LAURICHESSE H, BOUCHER D: Androgenic activity in 15-day-old male rats: role of the maternal pineal gland. Biol Reprod 46: 386-391, 1992.

KINSON GA, LIU CC: Further evidence of inherent testicular rhythm in the laboratory rat. $J$ Endocrinol 56: 337-338, 1973.

KLEIN DC: Evidence for the placental transfer of ${ }^{3}$-H-acetyl-melatonin. Nat New Biol 237: 117-118, 1972.

LANG U: Melatonin and puberty. Pineal Res Rev 4: 199-243, 1986. 
MARTÍNEZ-SORIANO F, RUIZ-TORNER A, ARMAÑANZAS E, VALVERDE-NAVARRO AA: Influence of light/dark, seasonal and lunar cycles on serum melatonin levels and synaptic number of the pineal gland of the rat. Histol Histopathol 17: 213-222, 2002.

MOCK EJ, KAMEL F, WRIGHT WW, FRANKEL AI: Seasonal rhythm in plasma testosterone and luteinizing hormone of male laboratory rat. Nature 256: 61-63, 1975.

MOCK EJ, FRANKEL AI: A seasonal influence on testes weight and serum gonadotropin level of the mature male laboratory rat. Biol Reprod 18: 772-778, 1978.

OJEDA SR, ANDREWS WS, ADVIS JP, SMITH-WHITE S: Recent advances in the endocrinology of puberty. Endocr Rev 1: 228-257, 1980.

OKATANI Y, OKAMOTO K, HAYASHI K, WAKATSUKI A, TAURA S, SAGARA Y: Maternal-fetal transfer of melatonin in pregnant women near term. J Pineal Res 25: 129-134, 1988.

OKATANI Y, WAKATSUKI A, OTUKONYONG EE, MIYAHARA Y: Effect of prenatal melatonin exposure on gonadotropins and prolactin secretion in male and female rat pups. Eur J Pharmacol 424: 229-235, 2001.

PAYNE AH, KELCH RP, MURONO EP, KERLAN JT: Hypothalamic, pituitary and testicular function during sexual maturation of the male rat. $J$ Endocrinol 72: 17-26, 1977.

PÉREZ-CASAS A, VILLA E, BENGOECHEA ME: Simple technique of pinealectomy for rats without alterations in the hypothalamus drainage. Congresus Anatomicus Europensis, Prague. Argumenta Communicatorum 1979, pp 313.

PESCHKE E, PESCHKE D, HUHN C: Circannual morphometric investigations of the rat suprachiasmatic nucleus after pinealectomy, ganglionectomy and thyroidectomy. Brain Res 740: 81-88, 1996.

PESCHKE E, TEICHMANN J, PESCHKE E: Pineal influence on annual nuclear volume changes in ventromedial hypothalamic nucleus (VMH) neurons of the male Wistar rat. Chronobiol Int 17: 15-28, 2000.

REITER RJ: The pineal gland and its hormones in the control of reproduction in mammals. Endocr Rev 1: 109-131, 1980.

REUSS S: Components and connections of the circadian timing system in mammals. Cell Tissue Res 285: 353-378, 1996.

SANTIAGO-MORENO J, GONZÁLEZ-BULNES A, GÓMEZ BRUNET A, DEL CAMPO A, PICAZO R, LÓPEZ SEBASTIÁN A: Nocturnal variation of prolactin secretion in the mouflon (Ovis gmelini musimon) and domestic sheep (Ovis aries): seasonal changes. Animal Reprod Sci 64: 211-219, 2000.

SCHULTE BA, SEAL US, PLOTKA ED, LETELLIER MA, VERME LJ, OZOGA JJ, PARSONS JA: The effect of pinealectomy on seasonal changes in prolactin secretion in the white-tailed deer (Odocoileus virginianus borealis). Endocrinology 108: 173-178, 1981.

TRESGUERRES JAF, ESQUIFINO AI: Dissociation in LH and FSH regulation in a hyperprolactinaemic model: Interrelationship between gonadotropin and prolactin control. $J$ Endocrinol 90: 41-51, 1981.

VANĚČEK J, PAVLÍK A, ILLNEROVÁ H: Hypothalamic melatonin receptor sites revealed by autoradiography. Brain Res 435: 359-362, 1987.

VÁZQUEZ N, DEBELJUK L, DÍAZ E, FERNÁNDEZ C, DÍAZ B: Seasonal changes of SP and NKA in frontal cortex, striatum and testes in the rat. Role of maternal pineal gland. Peptides 25: 997-1004, 2004a.

VÁZQUEZ N, DEBELKUK L, DÍAZ E, FERNÁNDEZ C, DÍAZ B: Influence of maternal pineal gland on the developmental pattern of neurokinin A (NKA) and substance P (SP) in male-rat-offspring. Relationship to the season of the year. Neurosci Lett 368: 243-248, 2004b.

WEAVER DR, RIVKEES SA, REPPERT SM: Localization and characterization of melatonin receptors in rodent brain by in vitro autoradiography. J Neurosci 9: 2581-2590, 1989.

WONG CC, DÖHLER KD, ATKINSON MJ, GEERLINGS H, HESCH RD, VON ZUR MÜHLEN A: Circannual variations in serum concentrations of pituitary, thyroid, parathyroid, gonadal and adrenal hormones in male laboratory rats. $J$ Endocrinol 97: 179-185, 1983.

YUAN H, LU Y, PANG SF: Binding characterizes and regional distribution of $\left[{ }^{125} \mathrm{I}\right]$ iodomelatonin binding sites in the brain of the human fetus. Neurosci Lett 130: 229-232, 1991. 
ZUCKER I, LEE TM, DARK J: The suprachiasmatic nucleus and annual rhythms of mammals. In: Suprachiasmatic Nucleus - The Mind's Clock. DC KLEIN, RY MOORE, SM REPPERT (eds), Oxford University Press, New York, 1991, pp 246-259.

\section{Reprint requests}

Beatriz Díaz López, Dpto. Biología Funcional, Área Fisiología, Facultad de Medicina, Universidad de Oviedo, C/Julián Clavería, 6, 33006, Oviedo, Spain, Fax: (34)-985103072. E-mail: beatrizd@correo.uniovi.es 